\title{
Where would we be without the pharmaceutical industry? A service user's view
}

There was a time in my life, not that long ago, when I could have given a very simple answer to this question. Where would I have been without pharmaceutical companies, specifically without Wyeth? Life was terrible with the pills, but I dared not contemplate it without them.

For six years I took lorazepam. It took me a year to get over its worst effects. I was very lucky. By chance I was able to go on a well-worked-out withdrawal programme linked with a research project where we were told it was harder coming off lorazepam than heroin. There was a group of us - the others all women. I don't think any of us felt we could have done it on our own. One young woman didn't last the course. An older woman with enormous courage did. We called her Dot, after the character in East Enders. Shortly afterwards, she threw herself from the top of a high-rise building. They didn't tell the rest of us because they were worried about our recovery, so we couldn't even go to her funeral.

I was prescribed lorazepam for my anxiety, panic attacks and depression, because there wasn't a system of rapidly getting into place the alternatives which we know work - but which I then had no knowledge or understanding of. What must all this have cost, just for one individual, let alone the many thousands we know make such terrible journeys? What did the withdrawal programme cost? What did it all cost in terms of lost opportunities to contribute, in terms of individual and family misery?

\section{The survivors' movement}

I became involved in the mental health service survivors movement in the late 1980s. I realised how the dominance of the pharmaceutical industry had affected it. It's this dominance we must seriously consider.

Such were the damaging effects which many service users associated with psychotropic drugs, that initially one of the concerns of many members of the survivors' movement was to stop taking their drugs and to encourage others to do the same. Pharmacological dominance encouraged this because of the mental health system's over-reliance on drugs and their crude usage in practice. Of course many drugs (and the way they were and are actually used) reinforce this attitude because of what are coyly called their 'side-effects'. It's hardly surprising if there was an overreaction.

More recently survivor activists have been able to consider the pluses and minuses of drug therapies and particular drugs; to produce and call for reliable, independent information; to challenge overprescription and inappropriate mixed prescription; to encourage each other to assert the right to demand and receive the particular drugs in the particular quantities that might work best for them individually; to ask for newgeneration drugs when they are what work best, without discrimination on grounds of cost, and to highlight and campaign against the discriminatory ways in which drugs are used on Black people and minority ethnic groups.

As service users grow in confidence and expertise, mainly through working together and gaining collective knowledge, we can make the best use of chemotherapy. We can use it how it might be best for us. We can escape the inappropriate dominance it has developed. Its claims must be checked more rigorously, its effects more determinedly monitored and independently reported. The drugs industry has to feel it is there to serve service user and community interests, rather than vice versa.

\section{Collusion with the drugs industry}

We must be honest about the way the whole mental health system is based on a collusive relationship with the drugs industry. Doctors sometimes complain about patients demanding prescriptions. When little else is readily on offer, what else can we expect? When general practitioner consultations are so brief, is it surprising if the first port of call is a prescription? There is a symbiotic and unhelpful relationship still at work between medicine and pharmaceutical companies which reinforces the disproportionate role of medication. The emphasis is wrong. Policy-makers, politicians, managers and professionals have all had a part to play in generating an overreliance on medication as a response to madness and distress. Over and over again, we hear how much all groups of service users want the choice of discussing treatments, in particular complementary approaches. But what you can expect, and what are still most readily available are the chemical responses.

The mental health system must change. What likelihood is there of this happening so long as mental health policy and practice are based on a grossly outmoded idea of 'mental illness', a distorting mirror held over the experience, emotions, behaviour and perceptions it is attached to? Unsurprisingly, the response to a diagnosis of 'illness', which highlights people's incapacity, pathology and deviance, is medication. We have to move on to the social approaches to distress - based more on ideas of support than treatment - that are beginning to be shown and experienced by mental health service users as working and helping. We need to pay more attention to holistic rather than medicalised understandings of people and their needs. We need to challenge the discrimination 
mental health service users routinely face and which results in impoverishment, exclusion, stigma and damaged self-esteem. We need to go beyond 'symptoms' to relationships, activity, learning, recreation and social role (Beresford, 2000)

Direct payments, where individual service users shape the package of support they receive and have charge of the money to pay for it, are showing how different things can be, how a much wider non-medicalised range of supports can help to keep you going, avoid crises and improve your life chances.

\section{The way forward}

So where would we be without the pharmaceutical companies? That's not really the question - although in an ideal world I'd like to see them taken under public control so they become accountable and the profit imperative doesn't determine what 'treatment' people receive. But until that day, what we have to be looking for is a new role and a new relationship with mental health policy and practice. It will be a different role, no longer a dominating one. But it should be a role that prioritises service user choice, independence, opportunity and quality of life.

\section{Declaration of interest}

The author is Professor of Social Policy at Brunel University and Chair of Shaping Our Lives, the national independent user-controlled organisation which receives its core funding from the Department of Health.

\section{Reference}

BERESFORD, P. (2002) Thinking about 'Mental Health': towards a social model. Journal of Mental Health, Editorial, 11 $581-584$.

Peter Beresford OSP, Tempo House, 15 Falcon Road, London SW112PJ 